\title{
Expectations of the pediatric intensive care unit team for the clinical pharmacist performance
}

\author{
Expectativas da equipe da unidade de terapia intensiva pediátrica quanto à \\ atuação do farmacêutico clínico
}

Andrea Q. Ungari ${ }^{1}$, Laura M. V. Pereira ${ }^{1}$, Davi C. Aragon ${ }^{2}$, Alexandra C. Abramovicius ${ }^{1}$, Ana T. A. Penna ${ }^{1}$, Débora A. Reis ${ }^{3}$, Márcia R. M. Malfará ${ }^{3}$, Talita C. Sato ${ }^{1}$, Aldaísa C. Forster ${ }^{4}$, Ana Paula C. P. Carlotti ${ }^{*}$

\begin{abstract}
Objective: We aimed to know the expectations of a pediatric intensive care unit staff for the activities to be undertaken by the clinical pharmacist, in order to plan her work along with the multidisciplinary team.

Study design: A cross-sectional study, involving the multidisciplinary team of the pediatric intensive care unit of a tertiary-care university hospital.

Method: A self-completion questionnaire containing questions regarding expectations of the pediatric intensive care unit staff for the role of the clinical pharmacist in the multidisciplinary team was applied to the team members, using a Likert-type scale response.

Results: The nursing assistants/technicians and physiotherapists showed higher expectation for issues related to administration of medications; for nurses, the expectation for the clinical pharmacist performance focused on issues related to prescription drugs, such as evaluation of antibiotic therapy, while physicians considered most important information on drug therapy, as notification of allergies related to drugs, information on period of validity of medicines and evaluation of drug administration by gastric or enteral tubes.

Conclusions: Team expectations varied according to the needs and routine of each professional category. The results of this study have contributed to implementation of the clinical pharmacy service in a Brazilian pediatric intensive care unit.
\end{abstract}

Keywords: Pharmacy Service, Hospital. Patient Care Team. Patient Safety. Pediatrics.

1. Pharmacist, Division of Pharmacy, Hospital das Clínicas, Ribeirão Preto Medical School, University of São Paulo, (HC-FMRP-USP). Ribeirão Preto, Brazil.

2. Statistician, Department of Pediatrics, Ribeirão Preto Medical School, University of São Paulo, (FMRP-USP). Ribeirão Preto, Brazil.

3. Clinical Pharmacist, Pediatric Intensive Care Unit, HC-FMRP-USP.

4. Associate Professor, Department of Social Medicine, FMRP-USP.

5. Associate Professor, Department of Pediatrics, FMRP-USP.

This research did not receive any financial support. The authors have no conflicts of interest to declare.
Correspondência Ana Paula de Carvalho Panzeri Carlotti. Department of Pediatrics, Hospital das Clínicas, Ribeirão Preto Medical School, University of São Paulo. Avenida dos Bandeirantes, 3900, 14049-900 - Ribeirão Preto - SP - Brazil. Aprovado em 23/08/2016 


\begin{abstract}
RESUMO
Objetivo: O objetivo do estudo foi conhecer as expectativas da equipe da unidade de terapia intensiva pediátrica quanto às atividades a serem realizadas pelo farmacêutico clínico a fim de planejar seu trabalho junto com a equipe multidisciplinar.

Desenho do estudo: Estudo transversal, envolvendo a equipe multidisciplinar da unidade de terapia intensiva pediátrica de um hospital universitário terciário.

Método: Um questionário autopreenchível contendo perguntas sobre as expectativas da equipe da unidade de terapia intensiva pediátrica em relação ao papel do farmacêutico clínico na equipe multidisciplinar foi aplicado aos membros da equipe, utilizando a escala de resposta do tipo Likert.

Resultados: Os auxiliares/ técnicos de enfermagem e fisioterapeutas mostraram maior expectativa em relação a questões relacionadas com a administração de medicamentos; para enfermeiros, a expectativa sobre o desempenho do farmacêutico clínico focou-se em questões relacionadas à prescrição de medicações, como a avaliação da antibioticoterapia, enquanto os médicos consideraram mais importantes informações sobre a terapia medicamentosa, como a notificação de alergias relacionadas às drogas, informações sobre o aprazamento de medicamentos e avaliação da administração de drogas por sonda gástrica ou enteral.
\end{abstract}

Conclusões: As expectativas da equipe variaram de acordo com as necessidades e a rotina de cada categoria profissional. Os resultados deste estudo têm contribuído para a implantação do serviço de farmácia clínica em uma unidade de terapia intensiva pediátrica brasileira.

Palavras-chave: Serviço de Farmácia Hospitalar. Equipe de Assistência ao Paciente. Segurança do Paciente. Pediatria.

\section{Introduction}

Iatrogenic injuries caused by medication errors are common among hospitalized patients. ${ }^{1,2}$ Some studies have evaluated the impact of interventions aimed at reducing these errors, including computerization of prescription and dispensation of drugs. ${ }^{3,4}$ However, teamwork as a strategy to cope with the intense process of specialization in health care has been shown as an alternative that may contribute to patient safety and efficacy of pharmacotherapy. ${ }^{2,5}$

Physicians are responsible for prescription, pharmacists for dispensing medications and nurses for administering them to the patient, and for a long time, these professionals have provided their assistance separately and not as a team. Currently, clinical pharmacists work in collaboration with other health professionals, ensuring greater safety for the patient through exchange of information and knowledge. ${ }^{6}$ In this context, the clinical pharmacist plays a key role in multidisciplinary teams of intensive care units, as patients' clinical characteristics, complexity of medications and large daily variation of prescriptions demand a comprehensive pharmacotherapeutic assessment. ${ }^{7-10}$
Several causes of medication errors resulting in harm to children have been reported in the literature, including individualized drug dosage based on weight, which can result in miscalculations, adult formulations for pediatric use, health services designed to better accommodate the adult population, children's inability to communicate effectively with health professionals about adverse events that might be occurring and failure to physiologically tolerate the consequences of medication errors. ${ }^{2}$

According to Kaushal et al., the potential risk for medication errors in pediatric patients is about three times higher than in adults. ${ }^{11}$ Indeed, there is evidence that clinical pharmacist interventions have a significant impact on reducing medication errors in pediatric hospitals. ${ }^{12}$ However, the inclusion of clinical pharmacists in the multidisciplinary team still faces difficulties in Brazil, since this work requires vast amounts of commitment in terms of time and effort, which precludes the recruitment of health professionals to perform this task. In addition, there is a shortage of specific training courses for clinical pharmacists in Brazil.

In our institution, a clinical pharmacist has been assigned to work in the pediatric intensive care unit since July 2014 . Thus, this study aimed to know 
the expectations of the pediatric intensive care unit staff for the activities to be undertaken by the clinical pharmacist, in order to plan her work along with the multidisciplinary team.

\section{Methods}

\section{Study design}

This was a cross-sectional study, which consisted of the application of a self-completion questionnaire to staff members of the pediatric intensive care unit of Hospital das Clínicas of Ribeirão Preto Medical School, University of São Paulo, Brazil. The study was approved by the Institutional Research Ethics Board (\#596/2014) and written informed consent was obtained from the participants.

The pediatric intensive care unit of Hospital das Clínicas of Ribeirão Preto Medical School had at the time of the study 77 staff members. The inclusion criteria were to work at the pediatric intensive care unit for at least six months and agreement to participate. Team members working in the unit for less than six months or those who refused to participate were excluded. Therefore, the survey was conducted with a convenience sample of 50 professionals who agreed to participate, including 24 nurs- ing assistants/ technicians, 13 nurses, eight doctors, three physiotherapists, one nutritional therapist and one administrative officer.

\section{Data collection}

The instrument used for data collection was a self-completion questionnaire developed by the authors, containing questions regarding expectations of the pediatric intensive care unit staff members for the role of the clinical pharmacist in the multidisciplinary team. The questionnaire was applied to the professionals, using a Likert-type scale response featuring three points: $1=$ unimportant or irrelevant; $2=$ important and $3=$ very important or essential, allowing participants to answer the questions according to varying degrees of importance of each item used to describe the task. The self-completion questionnaire was constructed based on a literature review regarding activities developed by the clinical pharmacist, and included 15 items $^{13}$ (Table 1). A pilot study was conducted with three professionals (a physician, a nurse and a nursing assistant) who were eligible for the study. The objective of the pilot study was to verify the understanding of the questions by the team members, intelligibility and clarity of the research questions as well as possible difficulties. No change was made in the questionnaire after the pilot study.

Table 1: Activities developed by the clinical pharmacist

1. Daily assessment of prescriptions

2. Evaluation of antibiotic therapy

3. Recommendation for dose adjustment according to kidney and liver function

4. Recommendation for replacement of non-standard prescription by standardized medication

5. Recommendation for replacement of route of administration, when necessary

6. Providing information for the prescriber on incompatibility between the drug and the diluent, drug stability and infusion time of drugs

7. Notification of known patient drug allergies

8. Monitoring of prescriptions (replacements, omissions and possible issues)

9. Checking for use of opioids and other psychotropic medications and their side effects

10. Checking for drug interactions that may cause damage or therapeutic failure

11. Drug Reconciliation: reconciling prescribed medications with those already in use by the patient

12. Provision of pharmaceutical care at hospital discharge

13. Providing information on period of validity of medicines

14. Evaluation of drug administration by gastric or enteral route, including location of the tube and drug absorption, and whether it is possible to triturate the drug

15. Providing information about drugs that may cause phlebitis 


\section{Data analysis}

Data were analyzed by correspondence analysis, which consists of a multivariate statistical method that allows measuring and visualizing the degree of association between a set of categories of qualitative variables. When applied to the analysis of the responses of the study questionnaire, it indicates the degree of association of different items on a Cartesian graph called correspondence map. In correspondence analysis, the total variation of the data is called inertia, which is decomposed in each axis (or dimension) of the graph. Thus, the inertia associated with each dimension of the graph tells us what proportion of the total variation is explained by that axis. ${ }^{14}$

\section{Results}

Figure 1 shows the correspondence map generated from correspondence analysis of the responses to the 15 questions. The coordinates of the questionnaire responses and professional categories are in dimensions 1 and 2, which account for 71\% of total inertia, i.e., a large part of the data variation is explained by these axes. Professional categories are represented in the correspondence map by abbreviations (NA, nursing assistants/ technicians; PHY physiotherapist; RN, nurse; MD, physician; OP, other professionals), where the numbers relate to the question of the questionnaire and the letter accompanying them refers to the degree of importance ( $a$, of little importance or irrelevant; b, important; c, very important or essential). The correspondence of a professional category with the questionnaire responses is represented by the distance on the graph. The items shown in the central area of the graph are associated to a greater degree.

As shown in Figure 1, nursing assistants/ technicians and physiotherapists had a higher expectation for issues related to drug administration as recommendation for replacement of route of administration, when necessary ( $5 b$ and $5 c$ ) and evaluation of drug administration by gastric or enteral tubes (14c). In addition, they considered drug reconcilia-

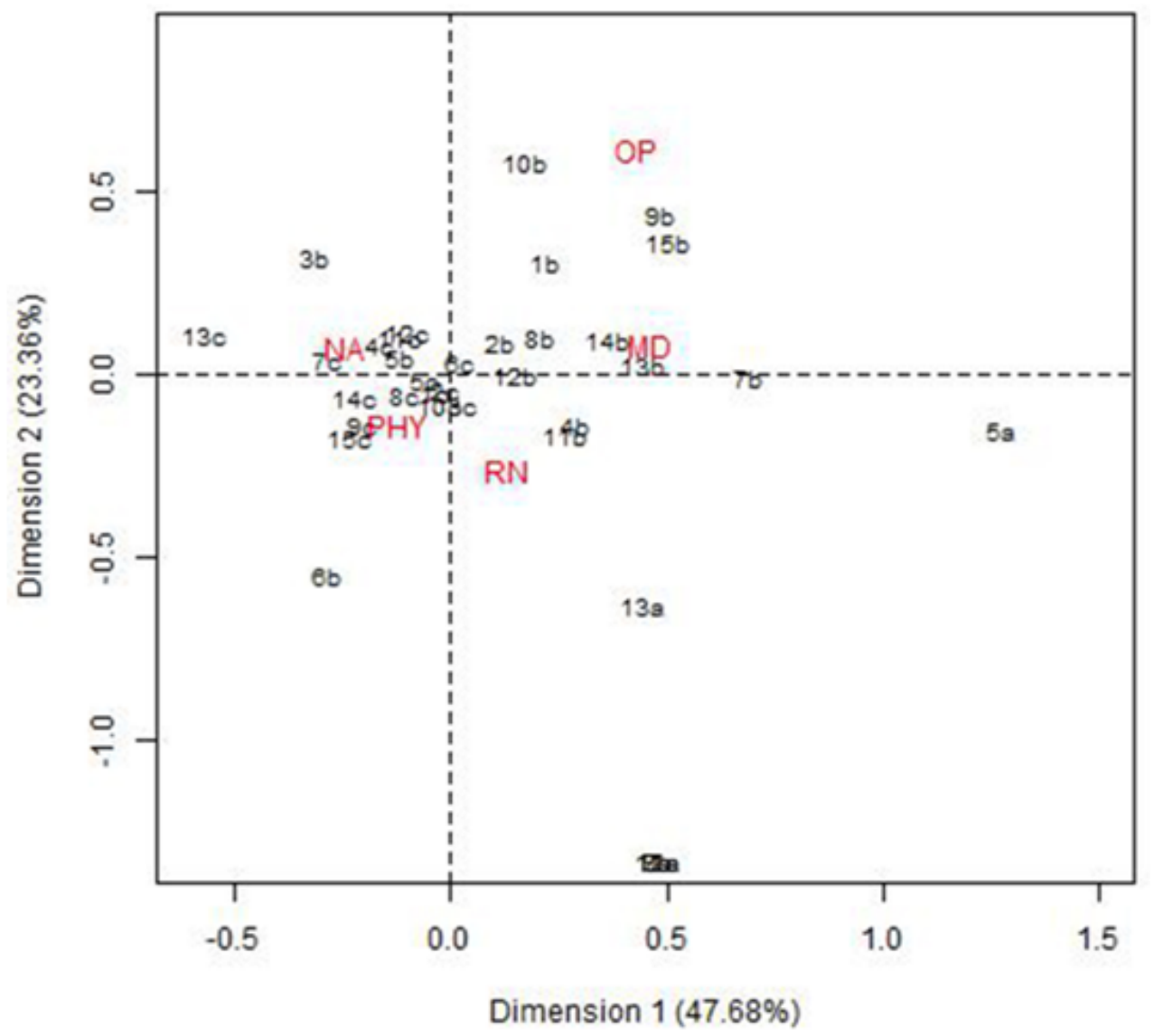

Figure 1: Correspondence map generated from correspondence analysis of questionnaire responses. 
tion (11c), notification of drug allergies (7c), monitoring of prescriptions (8c) and recommendation for replacement of non-standard prescription by standardized medication (4c) as very important or essential. Also, they considered the practice of pharmaceutical care at hospital discharge as very important (12c).

For nurses, the expectations for the clinical pharmacist performance focused on issues related to prescription drugs such as evaluation of antibiotic therapy (2c and $2 b$ ), recommendation for dose adjustment according to kidney and liver function (3c), recommendation for replacement of non-standard prescription by standardized medication (4b) and information about drug interactions that may cause damage or therapeutic failure (10c). They also considered very important or important information on incompatibility between the drug and the diluent, drug stability and infusion time of drugs (6c), daily assessment of prescriptions (1c), drug reconciliation (11b) and provision of pharmaceutical care at hospital discharge (12b).

On the other hand, physicians considered most important notification of drug allergies (7b), information on period of validity of medicines (13b) and evaluation of drug administration by gastric or enteral tubes (14b). Other professional categories expected the clinical pharmacist to check for the use of opioids and other psychotropic drugs (9b) and the presence of drug interactions that may cause damage or therapeutic failure (10b).

\section{Discussion}

Successful implementation of clinical pharmacy practice requires that clinical pharmacists work in collaboration with physicians, nurses and other members of the health care team. Therefore, it is important to know the expectations of the staff for the clinical pharmacists' roles to support an effective implementation of the clinical pharmacy service. In our study, the nursing staff judged most relevant issues related to drug administration while physicians considered information on drug therapy as more important. These differences in health care team expectations for the clinical pharmacist performance may be attributed to the specificities of function and routine of each professional category.
The pediatric intensive care unit staff of our institution was receptive to the clinical pharmacist's practice as most tasks to be undertaken by the clinical pharmacist were considered important or very important. Accordingly, the majority of physicians in Ethiopia were receptive to the clinical pharmacists' roles as drug therapy experts and patient educators on appropriate use of medications. ${ }^{15}$ In contrast, in Jordan, only $16.3 \%$ of physicians were comfortable with pharmacists suggesting the use of prescription medications to physicians. ${ }^{16}$ This discomfort has been attributed to lack of interaction among the health care professionals, as more than a third of physicians stated they rarely interacted with pharmacists. However, clinical pharmacists must work closely with physicians and other members of the health care team in order to optimize drug therapy and improve patient's outcome. ${ }^{17,18}$

In North America, clinical pharmacy was characterized in the 60 's, aimed at promoting safe and rational use of medications and cost savings. In Brazil, the area of clinical pharmacy has recently expanded. In February 2010, the Board Resolution from the National Health Surveillance Agency (ANVISA) included pharmaceutical assistance at bedside as part of the multidisciplinary care within the minimum requirements for operation of intensive care units (Ministério da Saúde, Agência Nacional de Vigilância Sanitária, Resolução-RDC no 7, de 24 de fevereiro de 2010). In addition, since 2014, a residency program in Clinical Pharmacy and Pharmaceutical Care at the Faculty of Pharmaceutical Sciences of the University of São Paulo has been established. Moreover, in a large tertiary-care hospital in São Paulo, a clinical pharmacy service showed a positive impact in rational use of medications and patient safety. ${ }^{19}$ Hence, urgent action and investments are needed to facilitate implementation of clinical pharmacy services in Brazil.

The main limitation of this study includes the lack of a comparison group because the research was designed specifically for the pediatric intensive care unit. However, the study is innovative as it showed the expectations of the professional team that have contributed to direct the activities of the clinical pharmacist and to the implementation of the clinical pharmacy service in a pediatric intensive care unit of a tertiary-care university hospital. 


\section{Conclusion}

The expectations of the pediatric intensive care unit multidisciplinary team for the clinical pharmacist performance varied according to the needs and practice of each professional category. The results of this study have contributed to implementation of the clinical pharmacy service in a Brazilian pediatric intensive care unit.

\section{References}

1. Bates DW, Cullen DJ, Laird N, Petersen LA, Small SD, Servi $D$, et al. Incidence of adverse drug events and potential adverse drug events. Implications for prevention. ADE Prevention Study Group. JAMA. 1995; 274: 29-34.

2. Cunningham KJ. Analysis of clinical interventions and the impact of pediatric pharmacists on medication error prevention in a teaching hospital. J Pediatr Pharmacol Ther. 2012; 17: 365-73.

3. Davydov L, Caliendo GC, Smith LG. Analysis of clinical intervention documentation by dispensing pharmacists in a teaching hospital. Hosp Pharm 2003; 38(4): 346-50.

4. Bates DW, Teich JM, Lee J, Seger D, Kuperman GJ, Ma'Luf $\mathrm{N}$, et al. The impact of computerized physician order entry on medication error prevention. J Am Med Inform Assoc. 1999; 6: 313-21.

5. Peduzzi M. Equipe multiprofissional de saúde: conceito e tipologia. Rev Saúde Pública. 2001; 35: 103-9.

6. Araujo RQ, Almeida SM. Farmácia clínica na unidade de terapia intensiva. Pharmacia Brasileira (booklet). Comissão de Farmácia Hospitalar do Conselho Federal de Farmácia. Novembro/Dezembro 2008.

7. Larochelle JM, Ghaly M, Creel AM. Clinical pharmacy faculty interventions in a pediatric intensive care unit: an eightmonth review. J Pediatr Pharmacol Ther. 2012; 17: 263-9.

8. Leape LL, Cullen DJ, Clapp MD, Burdick E, Demonaco HJ, Erickson JI, Bates DW. Pharmacist participation on physician rounds and adverse drug events in the intensive care unit. JAMA. 1999; 282: 267-70.
9. Kaboli PJ, Hoth AB, McClimon BJ, Schnipper JL. Clinical pharmacists and inpatient medical care: a systematic review. Arch Intern Med. 2006; 166: 955-64.

10. Moffett BS, Mott AR, Newlson DP, Gurwitch KD. Medication dosing and renal insufficiency in a pediatric cardiac intensive care unit: impact of pharmacist consultation. Pediatr Cardiol. 2008; 29: 744-8.

11. Kaushal R, Bates DW, Landrigan C, McKenna KJ, Clapp MD, Federico F, Goldmann DA. Medication errors and adverse drug events in pediatric inpatients. JAMA. 2001; 285: 2114-20.

12. Fernández-Llamazares CM, Calleja-Hernandez MA, Manrique-Rodriguez $S$, et al. Impact of clinical pharmacist interventions in reducing paediatric prescribing errors. Arch Dis Child. 2012; 97: 564-8.

13. Hayes BE. Medindo a satisfação do cliente: Desenvolvimento e uso de questionários. Tradução Luiz Liske, Rio de Janeiro: Qualitymark, 1995.

14. Greenacre MJ. Correspondence analysis in practice. London: Academic Press, 1993.

15. Alemayehu B, Elias A, Peggy O, Sultan S. Physicians' expectations on clinical pharmacists' roles in Jimma University Specialized Hospital, Southwest Ethiopia. IJPTP 2013; 4: 571-4.

16. Tahaineh LM, Wazaify M, Albsoul-Younes A, Khader $Y$, Zaidan M. Perceptions, experiences, and expectations of physicians in hospital settings in Jordan regarding the role of the pharmacist. Res Soc Adm Pharm. 2009; 5: 63-70.

17. Zillich AJ, Mcdonough RP, Carter BL, Doucette WR. Influential characteristics of physician/ pharmacist collaborative relationships. Ann Pharmacother. 2004; 38: 764-70.

18. Doucette WR, Nevins J, McDonough RP. Factors affecting collaborative care between pharmacists and physicians. Res Soc Adm Pharm. 2005; 1: 565-78.

19. Ferracini FT, Almeida SM, Locatelli J, Petriccione S, Haga CS. Implementation and progress of clinical pharmacy in the rational use of medicines in large tertiary-care hospital. Einstein. 2011; 9: 456-60. 